\title{
Hume and the Problem of Causation
}

\section{Document Version}

Accepted author manuscript

Link to publication record in Manchester Research Explorer

\section{Citation for published version (APA):}

Beebee, H. (2016). Hume and the Problem of Causation. In The Oxford Handbook of Hume (Oxford handbooks). Oxford University Press.

\section{Published in:}

The Oxford Handbook of Hume

\section{Citing this paper}

Please note that where the full-text provided on Manchester Research Explorer is the Author Accepted Manuscript or Proof version this may differ from the final Published version. If citing, it is advised that you check and use the publisher's definitive version.

\section{General rights}

Copyright and moral rights for the publications made accessible in the Research Explorer are retained by the authors and/or other copyright owners and it is a condition of accessing publications that users recognise and abide by the legal requirements associated with these rights.

\section{Takedown policy}

If you believe that this document breaches copyright please refer to the University of Manchester's Takedown Procedures [http://man.ac.uk/04Y6Bo] or contact uml.scholarlycommunications@manchester.ac.uk providing relevant details, so we can investigate your claim.

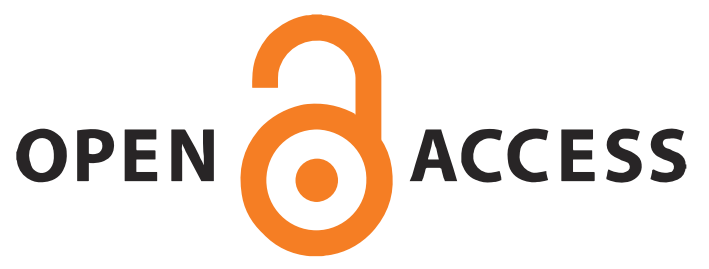




\section{Hume and the Problem of Causation}

Helen Beebee

Please do not cite this version. The published version is: Hume and the Problem of Causation', in P. Russell (ed.), The Oxford Handbook of Hume (New York: OUP, 2016)

\section{Introduction}

It is in good part due to Hume that causation has been regarded as problematic by analytic philosophers in the last hundred years or so. Hume's own major problem when it comes to causation is that of understanding the idea of 'necessary connection' - a crucial component of the idea of causation, he thinks, but one whose impressionsource he needs to spend a large part of Book I of the Treatise attempting to locate. Historically the majority of commentators have taken Hume's eventual conclusion to be that an objective, mind-independent necessary connection between causes and effects is unintelligible. Since the impression-source of the idea of necessary connection turns out to be our own mental activity and not sensation, that idea cannot latch on to any mind-independent feature of reality: necessity turns out to be a product of our own minds. So whatever we might think we are doing when we engage in causal talk and thought, we are not referring to mind-independent necessity.

On the other hand, the objective features that Hume does take our causal thought and talk to imply - namely contiguity, temporal priority and constant conjunction - are generally agreed to be insufficient to ground the truth of causal claims. Writing exactly a hundred years ago, Bertrand Russell argues that Hume's 'constant conjunctions' or exceptionless regularities are in fact rarely to be found in nature (1912-13); and there are standard problems for a 'naïve regularity theory' of the kind Hume is sometimes thought to be proposing, even setting aside Russell's complaint. In particular, there is the problem of accidental regularities (where $A$ s are constantly conjoined with $B \mathrm{~s}$ but $A \mathrm{~s}$ do not cause $B \mathrm{~s}$ ) and the problem of the common cause (where, again, $A \mathrm{~s}$ are constantly conjoined with $B \mathrm{~s}$, but both are effects of a common cause, so that again $A$ s do not cause $B \mathrm{~s}$ ). Coming at the problem from a different angle, Elizabeth Anscombe famously argues that the conceptual connection between causation and regularity posited by Hume does not in fact exist and, contra 
Hume, that we do have a sensory impression of the relation between causes and effects after all (1971). Other philosophers have argued that causation is really not as indispensable a concept as Hume thought, following Russell's claim that its 'complete extrusion from the philosophical vocabulary [is] desirable' (1912-13, 1). Russell's claim here is motivated by the claim that "the word "cause" is ... inextricably bound up with misleading associations' (ibid.), chief among these being the associations with necessity and regularity that Hume identifies.

Most recent philosophical positions on the nature of causation can be seen as attempts to maintain the spirit of, or else take issue with, what Hume is alleged to have thought, with 'Humean' theorists offering refinements of the idea that causation 'in the objects' is at bottom merely a matter of constant conjunction or regularity (e.g. counterfactual and probabilistic theories) and 'anti-Humean' theorists claiming that, ontologically speaking, there must be more to causation than mere regularity (e.g. necessitarian views and powers-based accounts). In fact, however, Hume's words have proved to be susceptible to differing interpretations that fall on both sides of the 'Humean' and 'anti-Humean' divide: some commentators take Hume to endorse the claim that there is more to causation 'in the objects' than regularity. Indeed, some commentators take Hume to hold that causation is a matter of real, fully mindindependent necessary connections.

The interpretative problems encountered when we try to make sense of what Hume says about causation are the main focus of this chapter. I begin in $\S 2$ by briefly summarising Hume's journey, as it plays out in the Treatise, towards the location of the impression-source of the idea of necessary connection. In $\S 3$ I begin discussion of the interpretative divide just mentioned, which turns in large part on whether we hold Hume to a 'meaning-empiricist' position that appears to be entailed by his theory of ideas, and in particular by the 'Copy Principle' (see e.g. Winkler 2000, §2 and Millican, this volume, $\S 3)$. In $\S 3$ I focus on the meaning-empiricist interpretative options, which have in common the denial that the idea of causation can succeed in referring to any mind-independent feature of reality beyond contiguity, priority and constant conjunction. (Hume thus interpreted is sometimes referred to as 'Old Hume'.) In $\S 4$ I focus on versions of the 'sceptical realist' interpretation ('New Hume'), which take Hume to affirm rather than deny that claim. In $\S 5$, I briefly discuss Hume’s famous two definitions of causation, and in $§ 6$ I say something about 
the seemingly intractable nature of the interpretative dispute surrounding Hume's views on causation.

\section{The genesis of the idea of causation}

Early on in the Treatise, Hume notes that it is 'only causation, which produces such a connexion, as to give us assurance from the existence or action of one object, that 'twas followed or preceded by any other existence or action' (T 1.3.2.2/73-4). In other words, if our reasoning concerning 'matters of fact' - what is going on out there in the world - is to have any epistemic legitimacy, it must be causal reasoning: reasoning from causes to effects or vice versa. It is the causal relation between eating bread and nourishment that assures me that my toast will nourish rather than poison me, and it is the causal relation between a key being turned in the lock and a certain kind of sound - which I can now hear - that assures me that my front door has just been opened.

We therefore need to investigate our idea of causation, and - since Hume subscribes to the 'Copy Principle', according to which all our ideas are copies of impressions - our means for doing so is to uncover the impression from which it arises. He quickly concludes that contiguity (causes and effects are right next to each other in space and time) and priority (causes precede their effects) are part of our idea of causation, the impression-sources of these ideas having already been identified in $\mathrm{T}$ 1.2. But contiguity and priority cannot be the whole story: 'An object may be contiguous and prior to another, without being consider' $d$ as its cause. There is a NECESSARY CONNEXION to be taken into consideration; and that relation is of much greater importance' ( $\mathrm{T}$ 1.3.2.11/77). Finding no impression of necessary connection when inspecting any individual cause-effect pair, however - the place where one would expect to find it - he proceeds to 'beat about all the neighbouring fields' ( $T$ 1.3.2.13/78) in the hope that the searched-for impression will be found in an unexpected location, which indeed it does - eventually.

There now follows Hume's famous discussion of inductive or causal reasoning. We've already seen that beliefs about matters of fact that are not currently present to the memory or senses arise as a result of reasoning from causes to effects (or vice versa). Hume argues that that inference cannot be a matter of 'demonstration' or a priori inference more generally: just by inspecting a given event in isolation, we cannot draw any conclusions about what will happen next. ('There is no object, which implies the existence of any other if we consider these objects in themselves' ( $T$ 
1.3.6.1/86).) It is only once we have past experience of $A \mathrm{~s}$ being followed by $B \mathrm{~s}-$ that is, once we have experience of a constant conjunction of $A s$ and $B \mathrm{~s}$ - that we are able to infer that a $B$ will follow on observing an $A$; and this experienced constant conjunction together with the occurrence of an A still fails to imply the existence of a $B$. Hume concludes that the inference from cause to effect is a matter of brute psychological association, or, as he puts it in the Enquiry, 'CUSTOM or HABIT' (EU 5.1.5/43): once $A$ s and $B$ s are constantly conjoined in our experience, when confronted with an $A$ we come to expect a $B$ in just the same way as a dog comes to expect food on hearing the familiar sound of its bowl clanking on the kitchen floor.

How does all this aid our grip on the idea of causation, as opposed to the inference from causes to effects? Well, Hume's eventual conclusion in the famously contested section 'Of the idea of necessary connexion' (T 1.3.14; EU §7) is that it is the inference itself that supplies the impression-source. Hume here repeats his earlier claim that we can discern no necessary connections between objects considered in isolation: I cannot 'go any farther' than discerning contiguity and precedence, 'nor is it possible for me to discover any third relation betwixt these objects' ( $T$

1.3.14.1/155). However, 'where I find like objects always existing in like relations of contiguity and succession', this repetition 'produces a new impression, and by that means the idea [of necessary connection]' (ibid.): 'I find, that upon the appearance of one of the objects, the mind is determin' $d$ by custom to consider its usual attendant, and to consider it in a stronger light upon account of it relation to the first object. 'Tis this impression, then, or determination, which affords me the idea of necessity' ( $\mathrm{T}$ 1.3.14.1/156).

The shape of Hume's argument here is clear enough: there is no impression of necessary connection when we consider two 'objects' or events $a$ and $b$ in isolation, but there is such an impression when we consider $a$ and $b$ and have previously observed $A \mathrm{~s}$ and $B \mathrm{~s}$ to be constantly conjoined. Hence the impression cannot be an impression of sensation: repeated observation cannot plausibly be thought to enable us to discern some relation between $a$ and $b$ that was previously present but somehow invisible to us when we observed $A$ s being followed by $B \mathrm{~s}$. The only thing that has changed, and so might serve as the cause of the new impression, is a change in us, namely the acquisition of the expectation of a $B$ on observing an $A$. Hence that change - the habitual association of $A \mathrm{~s}$ and $B \mathrm{~s}$ - must be responsible for the impression of necessary connection. 
Several issues remain rather opaque, however. In particular, what are Hume's grounds for asserting that we 'cannot discern any third relation' on first observing our $A-B$ pair? And if the impression of necessary connection is an impression of reflection - a result of the operation of an internal psychological mechanism, rather than our experience of the external world - how does this affect our apparent ability to deploy the idea of necessary connection in our causal talk and thought as though we are speaking about the external world and not about our own minds?

I shall leave the latter question to the next section and here focus on the first, concerning Hume's grounds for asserting that that we 'cannot discern any third relation' on first observing our $A-B$ pair. At first sight - and indeed this is how he initially presents the matter in the Treatise - he appears simply to be making a brute appeal to phenomenology: 'When I cast my eye on the known qualities of objects, I immediately discover that the relation of cause and effect depends not in the least on them. When I consider their relations, I can find none but those of contiguity and succession' ( $\mathrm{T}$ 1.3.2.12/77). Later in $\mathrm{T}$ 1.3.14, however, it becomes clear that his grounds are not merely phenomenological:

Now nothing is more evident, than that the human mind cannot form such an idea of two objects, as to conceive any connexion betwixt them, or comprehend distinctly that power or efficacy, by which they are united. Such a connexion wou'd amount to a demonstration, and wou'd imply the absolute impossibility for the one object not to follow, or to be conceiv'd not to follow upon the other: Which kind of connexion has already been rejected in all cases. (T 1.3.14.13/1612)

Hume's point is made more succinctly - and right at the outset of his argument in the corresponding section of the first Enquiry: 'From the first appearance of an object, we never can conjecture what effect will result from it. But were the power or energy of any cause discoverable by the mind, we could foresee the effect, even without experience; and might, at first, pronounce with certainty concerning it, by the mere dint of thought and reasoning' (EU 7.7/63).

It seems, then, that Hume runs together two distinct claims. One is the claim that on first observing a given cause-effect pair we have no impression of any connection whatsoever between them. As he puts it in the Enquiry: 'The first time a 
man saw the communication of motion by impulse, as by the shock of two billiard balls, he could not pronounce that the one event was connected; but only that it was conjoined with the other' (EU 7.28/75). This claim is a straightforward

phenomenological claim for which Hume offers no further justification. The second is the weaker claim that on first observing our cause-effect pair we have no impression of a specific kind of connection between the two - or, perhaps more perspicuously, no impression of any feature of the cause that would enable us to infer with certainty that the effect will follow. (Galen Strawson (1989, Ch. 11) calls this feature the 'a priori inference-licensing property', or 'AP property' for short.) And Hume does offer justification for this claim, namely the fact that we can in fact draw no such inference on first observing the cause.

This is an important distinction because, as Mackie (1974, 12-13) notes, we really can distinguish between two different species of possible necessary connection here: what he calls 'necessity' ' and 'necessity' ${ }_{2}$ respectively. This terminology may not be the most apt, however, since it is unclear why we are forced to think of all possible 'ties' between causes and effects as a kind of necessary connection. Thus, for example, counterfactual analyses of causation characterise causes as necessary rather than sufficient conditions of their effects; such analyses therefore do not require that causes necessitate their effects. Perhaps more pertinently given their overtly antiHumean agenda, Anjum and Mumford (2011) argue both that causal relations are perceivable (2011, Ch.9), and that causation is not a matter of necessitation (2011, Ch.3).

While Hume seems to want to establish the stronger claim - that we have no impression of any 'tie' on first observing our cause-effect pair - as well as the weaker one (that we have no impression of an AP property), it is clear that his main interest lies in the weaker claim. This is because his main interest in causation is in its connection with inference. Causation, remember, is supposed to be the relation by which we (legitimately) form beliefs about what is not immediately present to the senses or memory; and it is doubtful whether a mere observable 'tie' between causes and effects would have any connection with our capacity to infer effects from causes. Such a tie between cause and effect would certainly not shed any light on the formation of the expectation of the effect given the impression of the cause, since a mere tie could, presumably, only be observed as part of the temporally extended sequence that includes both cause and effect. (I cannot see the dog tied to the 
lamppost unless I can see both dog and lamppost. I could perhaps see that the dog is tied to something if the lamppost were somehow hidden from view and I could only see the dog and the rope; but if my interest was, precisely, in what the dog is tied to, this would not be much help.) Moreover, if we think about extrapolation to other cases, knowing by observation that this $C$ caused an $E$ is only going to allow me to infer $E$ s from $C$ s in other cases if the fact that this $C$ caused an $E$ implies that all other $C$ s cause $E$ s as well; and this will only be so if the occurrence of a $C$ guarantees the occurrence of an $E$ and if, in addition, I can know this to be so on the basis of observing the single case; a weaker connection would not serve to legitimise the inference.

So while Hume's account provides a positive answer to the question he started with - what is the origin of the idea of necessary connection? - it also establishes an important negative conclusion, namely that we cannot detect any feature of the cause that would license a priori inference to the existence of the effect. This sets him in direct opposition to the Scholastics, for whom penetration into the essences of objects can be achieved through sensory experience, as well as the rationalists, for whom the same feat could be achieved through 'purely mental scrutiny' (Descartes 1641, 21). Hume takes himself to have shown that neither purely mental scrutiny of the idea of a particular cause nor the scrutiny of the cause itself, via sensory impressions, will deliver any knowledge of its effects - since if such knowledge were delivered, so too would be the idea of necessary connection. And no such idea is forthcoming from these sources: 'reason alone can never give rise to any original idea' (T 1.3.14.5/157), and nor - as we have seen - can an impression-source for the idea of necessary connection come from sensory experience.

\section{Hume as a meaning-empiricist}

While the story so far is relatively uncontroversial from an interpretative point of view, we are still a long way short of an account of what features we ascribe to the world when we deploy causal talk. We know the circumstances - both internal and external - that give rise to our ability to 'call the one object, Cause; the other, Effect' (EU 7.27/75), namely the impression of the cause together with repeated past experience of events similar to the cause being immediately followed by events similar to the effect. But what is it to 'call' one object a cause and another its effect?

The major obstacle to answering this question on Hume's behalf is, precisely, 
the discovery that the source of the idea of necessary connection is an impression arising from an internal, mental operation - 'the determination of the mind, to pass from the idea of an object to that of its usual attendant' (T 1.3.14.25/167). For this seems to suggest that in talking about causation we are really talking, at least in part, about our own state of mind, and not about the world. Indeed, Hume seems to say as much explicitly. Putting words into an imaginary objector's mouth, he says: 'What! the efficacy of causes lie in the determination of the mind! ... Thought may well depend on causes for its operation, but not causes on thought' ( $\mathrm{T}$ 1.3.14.26/167). He does not attempt to argue that this interpretation of his position is mistaken; instead, he merely notes that 'the case here is much the same, as if a blind man shou'd pretend to find a great many absurdities in the supposition, that the colour of scarlet is not the same with the sound of a trumpet, nor light the same with solidity' (T 1.3.14.27/168).

Hume accounts for the predicted unwillingness of his readers to agree with him on this score - their 'contrary biass' - as follows:

'Tis a common observation, that the mind has a great propensity to spread itself on external objects, and to conjoin with them any internal impressions, which they occasion, and which always make their appearance at the same time that these objects discover themselves to the senses. Thus as certain sounds and smells are always found to attend certain visible objects, we naturally imagine a conjunction, even in place, betwixt the objects and qualities, tho' the qualities be of such a nature as to admit of no such conjunction, and really exist no where ... the same propensity is the reason, why we suppose necessity and power to lie in the objects we consider, not in our mind, that considers them ... ( $\mathrm{T}$ 1.3.14.25/167).

Hume's metaphor of the mind's 'propensity to spread itself on external objects' has, as Peter Kail notes (2007, xxiii), spawned a further metaphor - that of projection which looms large in many discussions of Hume's views, not just on causation but also on morality, aesthetics and (most obviously) secondary qualities.

How might the notion of projection help us to get a handle on Hume's views about causation? Well, in the passage just quoted, projection - the mind's propensity to spread itself - is used to explain an error we are inclined to make: the error of supposing that 'necessity and power ... lie in the objects' and 'not in our mind'. The most obvious way to understand the nature of this error is as the error of supposing 
that causes really do have within themselves the AP property: a property such that, were we to be capable of detecting it, would enable us to infer the existence of the effect a priori. And we make the error because we project our own inferential habit the associative mechanism by which the impression of the cause engenders belief in the effect in our minds - onto the cause and effect themselves, so that we conceive (or rather we think we conceive) of the cause, just by itself, as the ground of the inference to the effect. That is, we conceive (or think we do) of the cause as possessing the AP property, when really, given the impression-source of the idea of necessary connection, causes cannot 'necessitate' their effects in this sense, since to suppose that they do would be to assume that the idea of necessary connection can latch onto mind-independent necessity - something Hume takes himself to have shown to be impossible, at least for beings like us. We are simply incapable of using the idea of 'necessary connection' to refer to such a thing, since any such idea would lack the required impression-source.

Is Hume thereby claiming that causation 'in the objects' - the world's contribution to the obtaining of causal relations - could not be any more than contiguity, priority and constant conjunction? This is a highly contentious question. Some authors think that he is claiming exactly that, and for the reason just given: contiguity, priority and constant conjunction exhaust the elements of the idea of causation that can refer to mind-independent features of reality, and so the contribution from the world to causation itself - which is, after all, simply whatever it is that our idea of causation refers to - can likewise only amount to these three features. This interpretative line holds Hume to a strict meaning-empiricist position, which ties the semantic content of our ideas directly to their impression-sources and so leaves no semantic scope for reference to features of reality that lie beyond our sensory capacities.

I consider some objections to this line of interpretation in the next section, but for now 1 shall briefly rehearse the interpretative options that hold Hume to something like this strict meaning-empiricist line. There are two main lines of thought here. What I have elsewhere called the 'traditional' interpretation (Beebee 2006, Ch.5) largely on the grounds that it is the view most commonly attributed to Hume amongst philosophers more widely, even if it is less frequently specifically endorsed amongst Hume scholars - takes Hume to be offering a version of the 'regularity theory' of causation (see Psillos 2009): to say that $a$ caused $b$ is simply to say that $A$ s and $B \mathrm{~s}$ 
stand in the relations of contiguity, priority and constant conjunction (and that $a$ and $b$ both occur). Versions of this interpretative position are held by, for instance, Mackie (1974), Beauchamp and Rosenberg (1981), Wilson (1986) and Garrett (1997, 2009).

By contrast, the 'projectivist' interpretation (Coventry 2006; Beebee 2006, Ch. 6), while agreeing with the traditional interpretation that causation 'in the objects' is exhausted by contiguity, priority and constant conjunction, takes Hume's metaphor of the mind's propensity to spread itself on the world not merely to explain an error that of supposing that causes possess the AP property - but to point towards a positive thesis. When discussing taste, Hume says that taste 'has a productive faculty, and gilding and staining all natural objects with the colours, borrowed from internal sentiment, raises in a manner a new creation' (EM App. I/294). The projectivist interpretation takes Hume to have the same view about our habit of inferring effects from causes: in our causal talk we judge the world to be a world of necessary connections, but not by representing it as containing some mind-independent feature; rather, necessary connection is a 'new creation' with which we gild or stain the world. So the world is, as it were, adequate to our causal talk not by containing genuine necessary connections (indeed, given meaning empiricism we are not so much as capable of ascribing such features to reality), but by being adequate - via constant conjunction - to the inferential habit that we project onto it.

The central disagreement between these two lines of interpretation, then, is over whether or not Hume takes the idea of necessary connection, which, both sides agree, fails to represent any mind-independent feature of reality, to nevertheless play an essential semantic role in our idea of causation.

\subsection{Hume as a regularity theorist}

Let's start with the traditional interpretation. The major element of disagreement between the different versions thereof concerns the precise role of the idea of necessary connection. Recall that Hume seems to think that this idea is a component of the idea of causation - and, moreover, a component that is distinct from the idea of constant conjunction. How can this claim be squared with the claim that Hume takes causation to be merely a matter of constant conjunction (plus contiguity and priority)? One option (Mackie 1974) is to take Hume to be advocating a revision of the concept of causation: once we realise how utterly defective the idea of necessary connection 
is, the idea of causation should be 'cleaned up' so that the idea of necessary connection plays no part. ${ }^{\mathrm{i}}$ A second option (Beauchamp and Rosenberg 1981; Wilson 1986 ) is to hold that the idea of necessary connection merely plays a role in the assertibility of causal claims, and not in their truth conditions. A third option, pursued by Garrett $(1997,2009)$ is to exploit the thought that the idea of causation is an abstract idea; the answer to the question of what role the idea of necessary connection plays in the idea of causation then becomes somewhat nuanced. I shall briefly discuss Garrett's view below, but first let's consider some of the textual evidence for and against the traditional interpretation.

The major piece of textual evidence standardly adduced in favour of the traditional interpretation is Hume's famous two definitions of causation, which appear in the Treatise as follows:

We may define a CAUSE to be 'An object precedent to and contiguous with another, and where all the objects resembling the former are plac'd in like relations of precedency and contiguity to those objects, that resemble the latter'. If this definition be esteem'd defective, because drawn from objects foreign to the cause, we may substitute this other definition in its place, viz. 'A CAUSE is an object precedent and contiguous to another, and so united with it, that the idea of the one determines the mind to form the idea of the other, and the impression of the one to form a more lively idea of the other'. (T 1.3.14.31/170)

The two definitions have spawned a huge amount of interpretative controversy, to which I return in $\S 5$. For now, however, note that neither definition mentions the idea of necessary connection. Of course the mental process that gives rise to that idea is mentioned in the second definition, but the idea itself is absent. Moreover, the first definition appears to be a straightforward statement of the regularity theory.

On the negative side, one major alleged source of evidence against the traditional interpretation - and against the projectivist line as well - is Hume's repeated apparent references to secret or unknown powers, forces or 'principles', especially in the first Enquiry. Interpreters who cast Hume as a 'sceptical realist' take these references to be good evidence that he in fact holds that there really is something more to causation 'in the objects' than mere regularity, even though that 'something more' is something that lies forever beyond our grasp. 
I return to this debate in $\S 4$ below. More important for the purposes of adjudicating between the traditional and projectivist interpretations is Hume's apparent insistence that the idea of necessary connection is a part of the idea of causation, and his disinclination to retract that insistence (pace Mackie) or to take our causal talk to be irredeemably defective (pace Stroud) even once its source in our mental activity has been discovered. After all, his response to 'What! the efficacy of causes lie in the determination of the mind!' is not to claim that his view has no such consequence, or to agree with his imagined opponent that the idea of causation is indeed, on his own view, absurd; rather, it is to point out that the view attributed to him only seems absurd if we are labouring under the misapprehension that the idea of necessary connection has an external rather than an internal source.

Garrett's position is worth examining in more detail, since Garrett attempts to deflect the above worry by claiming that there is a sense in which the idea of necessary connection can be a 'part of' the idea of causation, consistent with causation's being defined in terms that do not appeal to the idea of necessary connection. As I said, Garrett's position takes as its starting point the fact that for Hume the idea of causation is an abstract idea: an idea capable of representing things that do not perfectly resemble one another. According to Hume, 'abstract ideas are really nothing but particular ones, consider'd in a certain light; but being annexed to general terms, they are able to represent a vast variety, and to comprehend objects, which, as they are alike in some particulars, are in others vastly wide of each other' ( $\mathrm{T}$ 1.2.3.5/34). Garrett explains this as follows:

Upon noticing a resemblance among objects, Hume claims, we apply a single term to them all, notwithstanding their differences. The term is directly associated with the determinate idea of a particular instance. This determinate idea nevertheless achieves a general signification - and hence serves as an abstract idea - because the term also revives the 'custom' or disposition to call up ideas of other particular instances. $(1997,103)$

Garrett calls the set of particular instances to which the relevant term refers its 'revival set' (1997, 103).

The contrast here is with Locke, for whom abstract ideas are formed, as the name suggests, by a process of abstraction: we form a single abstract idea - cat, say - 
by abstracting away from all the variations between particular cats so that we are left with an idea that just includes everything that cats have in common. Hume disagrees (as did Berkeley before him $(1710, \S 11)$ ), holding instead that our abstract idea cat is in fact the idea of a particular cat, which of course will have various features (size, colour of fur, etc.) that are not common to all cats. The word 'cat' is associated with this idea, but in a special way: the word can also 'call up' other ideas of other particular cats, those cats being the 'revival set' of the word 'cat'. So for example while my idea cat might be the idea of a medium-sized tabby, I don't come to believe that all cats are medium-sized tabbies, because the word 'cat' calls to mind other members of the revival set - lions, Siamese, and so on - which of course consists of cats of various different sizes, breeds and species.

A definition of an abstract idea specifies what it is that all members of the revival set have in common - so the definition of an abstract idea will coincide with the content of a Lockean abstract idea (four paws, furry, etc.) without actually fully describing the content of any idea, since, again, any idea of a cat will include specific size, colour, and so on.

In the case of the abstract idea of a relation $R$, Garrett claims that the 'revival set' is constituted by all the pairs of objects or events (or whatever) that are related by $R$. In the case of causation, what the members of the revival set have in common is that the first member of each pair stands in the relations of contiguity, priority and constant conjunction to the second member; this thus constitutes the definition (or rather, as we shall see in the next section, one of two alternative definitions) of causation.

How, if at all, does the idea of necessary connection get in on the act, given Garrett's interpretation of Hume? Well, Garrett (2009, 82-3) distinguishes between an idea's being part of a complex (but non-abstract) idea, and its being a part of a concept, where 'concept' is a less misleading name for Hume's abstract idea (since an abstract idea, on Hume's view, is simply a particular idea that plays the special role of 'standing for' all other members of the revival set: it has 'general signification'). Garrett claims that the sense in which the idea of necessary connection is part of the concept of causation is that the 'idea is part of every idea in the revival set' (2009, 83). And it is true, he claims, 'that the idea of necessary connection is part [in the above sense] of at least many individuals' concept of CAUSATION' (ibid.). However, 'it is not essential to the concept of CAUSATION itself. For to overcome the projective 
illusion ... is not to change the pairs of objects whose ideas constitute the revival set of the idea of cause and effect, but only to correct the way in which those pairs are represented' (ibid.).

Garrett's thought here, I take it, is that the idea of necessary connection is not an 'essential' part of the concept of causation, and that this is because the abstract idea of causation, for those who have 'overcome the projective illusion', has as its revival set ordered pairs of objects (or events). And this gets to count as the same abstract idea as that had by those who have failed to overcome the illusion - for whom the idea of necessary connection $i s$ a part of the concept of causation - because both sets of concept-possessors have the very same pairs of objects figuring in their revival sets; it's just that those who are still in the grip of the projective illusion have something extra, but inessential, in there as well.

Garrett is surely right that for Hume the idea of causation is an abstract idea, and hence a particular idea 'consider'd in a certain light'. What is less clear is why the abstract idea of a relation $R$ is the revival set merely of pairs of particular objects or events of the form $\langle a, b>$, as opposed to the revival set of pairs of particular $R$-related events $\langle a R b\rangle$. It is the former claim that appears to render it impossible for Hume to think that the idea of necessary connection could be an essential part of the concept of causation, since in that case the revival set would have to have as members not ordered pairs of events but pairs of events related by necessary connection. (Suppose, for the sake of the argument, that necessary connection is both a genuine feature of mind-independent reality and an essential component of causation. Then the world might in principle lack that feature, and yet contain the very same pairs of events. Then the concept that merely picks out those pairs of events would fail to be the concept of causation, since it could apply to pairs of events that are not, in fact, causally related.)

The worry here is this. Garrett's position is, at first sight, hostage to the worry raised earlier against versions of the traditional interpretation generally: it excludes the idea of necessary connection from the idea of causation, contrary to what appear to be Hume's intentions. Or rather, it excludes the idea of necessary connection from a cleaned-up version of the concept of causation - the concept possessed by those who have overcome the projective illusion. And this fits poorly with Hume's apparent disinclination to strip the idea of necessary connection from the idea of causation, 
even once the projective illusion (of thinking that causes have the AP property) has been uncovered.

Garrett's implicit response to this worry seems to be that once we grasp the fact that for Hume the revival set for the abstract idea of a relation consists merely of ordered pairs, there is simply no room for the claim that the idea of causation might have as its revival set pairs related by necessary connection. But it is unclear why we should attribute this view of abstract ideas of relations to Hume; and in any case Garrett seems to concede that the concept of a relation can have as its revival set $R$ related events, since this is precisely what seems to be implied by the claim that 'the idea of necessary connection is part of at least many individuals' concept of CAUSATION'. Of course, Garrett thinks that the inclusion of the idea of necessary connection is 'not essential to the concept of CAUSATION itself', but without the claim that the revival sets of abstract ideas of relations are (essentially) sets of mere pairs of objects, this claim is unwarranted. Nonetheless, Garrett's account is an interesting attempt to maintain the spirit of the traditional interpretation while conceding some ground to its rivals by allowing a sense in which the idea of necessary connection might be part of the concept of causation.

\subsection{Hume as a projectivist}

Suppose we accept that Hume really does think that the idea of necessary connection is an ineliminable part of the idea of causation, and that the former idea fails to latch on to any mind-independent feature of reality. One direction this might take us in is towards a projectivist understanding of his position. On this view, projection - the 'spreading of the mind' - functions not merely as a causal explanation of our tendency to think of events as necessarily connected; it also plays an essential role in the semantics of 'cause', so that what it is to 'think of' events as necessarily connected is conceived in non-representational terms. (In fact - borrowing a term from Simon Blackburn and following Angela Coventry (2006) - 'quasi-realist' is perhaps a better term than 'projectivist'; see Joyce 2009, $\S 3$ for a useful explanation, in the moral case, of the relevant terms.) So the 'contrary biass' discussed above is the inclination to assume that the idea of necessary connection represents a feature of mind-independent reality, when in fact it does not.

One way to motivate the projectivist interpretation is to note that, arguably, Hume holds that the impression of necessary connection is projected onto cause-effect 
pairs, so that how such pairs look once the habit of inference has been acquired (this being responsible for the impression) is different to how they look on first observing them (see Beebee 2006, §4.3). Thus Hume's claim that '[a]ll events seem entirely loose and separate' (EU 7.26/74) is not to be read as a completely general claim, but as a claim only about how things seem prior to the establishment of the habit of inference; once the habit has been established the relevant pairs of events look, precisely, necessarily connected. And this is what prompts us to judge that they are necessarily connected: we 'then call the one object, Cause; the other, Effect' (EU $7.27 / 75)$.

The distinctive element of the projectivist interpretation is its understanding of what it is for two events to be judged to be necessarily connected. Consider an analogy with Hume's account of aesthetic judgement (discussed at greater length in Coventry 2006, 120-39; see also Beebee 2006, §6.2). Hume holds that beauty 'is no quality in things themselves: It exists merely in the mind which contemplates them' (ESY, 230). And yet Hume himself routinely adopts what (in a related context) Huw Price calls 'the objective mode of speech' $(1998,125)$ : Hume talks of 'real deformity' (ESY, 246), of 'beauties and blemishes' having 'influence' on individuals (ESY, 239), and so on. That is, he clearly takes the fact that beauty is in some sense in the eye of the beholder to be no bar to making true aesthetic claims that look for all the world as though they are attributions of aesthetic properties to objects outwith the mind.

A projectivist account of Hume's position on aesthetics squares this apparent circle by holding that aesthetic 'truth' is to be distilled from the normative standards that apply to aesthetic judgements. There are 'general rules of art', Hume says, that are 'founded only on experience, and on the observation of the common sentiments of human nature' (ESY, 232); and the verdicts of the 'true judges' - those critics who possess ' $[\mathrm{s}]$ trong sense, united to delicate sentiment, improved by practice, perfected by comparison, and cleared of all prejudice' and are therefore able to apply the rules appropriately - 'is the true standard of taste and beauty' (ESY, 241). It is existence of this standard, according to a projectivist line, that makes it appropriate to attribute truth and falsity to aesthetic judgements, despite the fact that those judgements fail to represent objects as possessing genuine intrinsic aesthetic properties. In other words, our aesthetic judgements project our aesthetic responses onto objects, and the truth or 
falsity of those judgements is determined by their conformity (or not) to the true standard of taste.

The intended analogy with the case of causation and necessary connection is straightforward. Again, we have something internal (though an impression of reflection rather than a sentiment) and the corresponding idea projected onto the world. And we have the causal analogue of the 'rules of art' - the contiguity, priority and constant conjunction requirements together with Hume's 'rules by which to judge of causes and effects' ( $\mathrm{T}$ 1.3.15). Those rules, correctly applied (perhaps by somebody akin to Garrett's 'idealised spectator'; see $\S 5$ below), deliver a 'true standard' for causation, which in turn renders our causal judgements truth-evaluable.

Two serious objections to the projectivist interpretation are, first, that there is virtually no direct textual evidence supporting it, and, second, that it ascribes to Hume a view - non-cognitivism - that a philosopher writing in the first half of the eighteenth century would, arguably, hardly have been in a position to so much as formulate. On the positive side, however, the interpretation does succeed in ascribing to Hume three theses for which there is evidence that he endorses: meaningempiricism, the thesis that the idea of necessary connection is an essential part of the idea of causation, and the thesis that our causal talk is not irredeemably defective. (As we have just seen, he does after all offer us 'rules by which to judge of causes and effects', and he consistently relies on causal claims elsewhere in his work.) Other interpretations ascribe at most two of these three theses to Hume. Of course, it is a matter of controversy which, if any, of the three theses really are endorsed by Hume; but evidence that all three should be ascribed to him is, a fortiori, evidence that the projectivist interpretation is correct.

The point about the lack of availability of a non-cognitivist position at the time Hume was writing might be mitigated somewhat by the thought that Hume's discussion of aesthetic judgement can reasonably be interpreted as a gesture towards something like a projectivist position in the aesthetic case. Even so, perhaps the best that can be said is that if Hume really does intend to endorse all three of the theses just described, then projectivism is the position he would have embraced, had he been in a position to do so.

\section{Rejecting meaning-empiricism: sceptical realism}


Recall from $\S 2$ that in the Treatise Hume apparently uses projection - the mind's propensity to spread itself -to explain an error we are inclined to make: it is 'the reason, why we suppose necessity and power to lie in the objects we consider, not in our mind, that considers them' ( $\mathrm{T}$ 1.3.14.25/167). This strongly suggests, of course, that Hume holds that necessity and power do not 'lie in the objects we consider'. However, in many other places - especially, but not exclusively, in the first Enquiry he makes plenty of realist-sounding claims: 'the particular powers, by which all natural operations are performed, never appear to the senses' (EU 5.3/42), 'the powers and forces, by which the [course of nature] is governed, [are] wholly unknown to us' (EU 5.21/54), and so on (see Strawson 1989, §§16-20 for many more examples). Hume seems, then, to be endorsing a realist position on causation (or at least on 'powers') - albeit a realism that is tinged with scepticism. There are real causal powers in nature, he seems to be saying, but their nature eludes us. Indeed, in the Enquiry section on the idea of necessary connection $(\S 7)$, where he argues for the same view about the impression-source of the idea of necessary connection as in the Treatise, he takes that view to reveal 'the surprizing ignorance and weakness of the understanding' (EU 7.29/76). (Other interpreters have of course denied that Hume's realist-sounding utterances are to be read as genuine endorsements of realism; see for example Jacobson 2000; Winkler 2000 and 2010, §3.)

Hume thus sometimes sounds more like a 'sceptical realist' - someone who believes in real causal powers but accepts that we cannot know their nature (and in particular, that we cannot perceive or detect them) - than a meaning-empiricist (that is, someone who holds that to talk of real, mind-independent causal powers is to 'talk without meaning'). And this is precisely the view that has been attributed to Hume by several commentators (e.g. Kemp Smith 1941; Wright 1983, 2000; Strawson 1989, 2001; Buckle 2001; Kail 2007). A common (though not universal) theme amongst such interpreters is that while Hume's own theory of ideas pushes him towards fullblown meaning-empiricism, he does leave scope for the ability to form a 'relative idea' of features of reality whose nature we cannot, thanks to our sensory limitations, fully grasp (see e.g. Flage 2000), and/or that we can coherently 'suppose' or 'conceive' that reality has such features despite lacking what Strawson calls 'positively contentful' ideas of those features $(1989, \S 12.2)$.

There are interesting and subtle differences between the different versions of the sceptical realist interpretation. For example, Strawson takes Hume to be a 
subjectivist about necessity $(1989, \S 15.3)$, but to hold nonetheless that our causal talk refers to real causal power, or 'Causation' as Strawson calls it, conceived as the feature of the world (nature unknown) that underpins its regularities. Buckle, by contrast, takes Hume to believe in underlying 'mechanisms' that endow objects with causal powers. But '[s]ince the mechanisms are inaccessible to perceivers like us, the powers of the objects must remain hidden: all that we can observe are their effects in the world, including their effects on us' $(2001,194)$. John Wright, by contrast again, takes Hume to believe in the AP property: when we make causal claims, we really do claim that the cause has a power that absolutely guarantees the effect.

A second dimension of variation concerns what kind of attitude Hume has towards real causal powers (however we cash out what, in Hume's view, a causal power is). One might be interested in showing why Hume himself believes in them for example, because such a belief would be entirely reasonable given his Newtonian heritage (see Buckle 2001, 210-11), or because he would have been persuaded by a philosophical argument to the effect that nature's regularities cannot be a matter of cosmic luck (Strawson 1989, 21; Craig 2000). Or one might be interested in showing how Hume's own avowed psychology and/or epistemology can deliver belief in real powers, so that the issue isn't whether or not Hume is convinced that they exist, but whether or not he has the resources to explain how we come to believe in them, given his story about the operation of the mind. Thus Wright holds that belief in the AP property is straightforwardly delivered by our habit together of inferring effects from causes: when we come, thanks to the establishment of that habit, to 'call the one object, Cause; the other, Effect', precisely what we do is ascribe the AP property to the cause (and not mistakenly so).

I have argued elsewhere that Wright's is the most convincing version of the sceptical realist interpretation (2006, Ch. 7); here I briefly explain what, on Wright's view, the projective 'error' is that Hume attributes to us when we 'suppose necessity and power to lie in the objects we consider, not in our mind, that considers them'. Wright's view is that the error is that of thinking that detectable necessary connections exist. Because of our tendency to 'spread the mind', we mistake an impression of reflection (the impression of necessary connection) for an impression of sensation, and so we are inclined to suppose that we are detecting the AP property, when really we are merely projecting. Nonetheless, the AP property is what we ascribe in our causal talk. We have an understandable tendency to be mistaken about 
the impression-source of the idea of necessary connection, but not about its content. The sceptical part of Hume's sceptical realism remains in place, however, since what we ascribe to the cause is only its having some feature or other, such that were we to be able to detect it we would be able to infer the effect a priori. The nature of that feature of course eludes us entirely: we cannot detect it, and so do not have a grasp of what it is really like (see Wright 2000, §4).

\section{The two definitions}

We saw in $\S 3.1$ above that Hume's two definitions - stated at T 1.3.14.31/170 and slightly reformulated, at EU 7.29/76-7 - have been cited as a major piece of evidence in favour of a meaning-empiricist reading, and in particular the traditional interpretation. On the other hand, Hume's preamble to the statement of the two definitions in the Enquiry, which says that 'the ideas which we form' concerning the causal relation are 'so imperfect' that 'it is impossible to give any just definition of cause, except what is drawn from something extraneous and foreign to it' (EU 7.29/76), have been taken by some authors to point not to meaning-empiricism but to the inadequacy of the definitions as reflections of the true nature of real causal powers, thanks to our cognitive limitations.

More generally, recently there have been various interpretations of the two definitions that reject the idea that they are intended to capture the meaning of 'cause' - an idea that is immediately problematic in any case, since they so clearly fail to be even co-extensive, let alone necessarily so. Here are the two definitions of the Treatise again:

(1) An object precedent to and contiguous with another, and where all the objects resembling the former are plac'd in like relations of precedency and contiguity to those objects, that resemble the latter.

(2) An object precedent and contiguous to another, and so united with it, that the idea of the one determines the mind to form the idea of the other, and the impression of the one to form a more lively idea of the other. ( $\mathrm{T} 1.3 .14 .31 / 170)$

(1) and (2) fail to be co-extensive since, first, two events might satisfy the constant conjunction requirement in (1) and yet fail to have been repeatedly observed by 
anyone, as required for (2) to hold; and, second, $A$ s and $B$ s might have been constantly conjoined in the experience of a particular observer, and yet fail to be constantly conjoined simpliciter, as required by (1).

One broad line of interpretation has been to think of the two definitions as specifications of the circumstances that prompt causal judgement. For example, Craig says that the definitions characterise the "circumstances under which belief in a causal connection arises, one concentrating on the outward situation, the other on the state of the believer's mind that those outward facts induce' $(1987,108)$. In similar vein, Garrett says: "we can define "cause and effect" either in terms of the constant conjunction that in fact produces the determination or transition ... or we can define "cause and effect" in terms of the association and inference' $(1997,106)$.

Garrett also argues that the definitions are in fact co-extensive. We can give (1) either an 'absolute' reading - referring to constant conjunction simpliciter - or a 'subjective' reading, where 'constant conjunction' means 'observed constant conjunction'. Correspondingly, we can read 'the mind' in (2) as the mind of an 'idealised' spectator - one who observes all and only representative samples of pairs of events, so that they will satisfy (2) if and only if (1) is satisfied - or, alternatively, as the mind of a normal observer, who may observe unrepresentative samples of pairs of events (a 'subjective' reading). Reading both definitions in the absolute/idealised spectator sense delivers coextensiveness, as does reading both in the subjective sense; the appearance of lack of coextensiveness is a function of the fact that we are inclined to give (1) an absolute reading and (2) a subjective reading (see Garrett 1997, 108$11)$.

A second interpretative position, defended in Beebee (2011), construes the two definitions as characterising two distinct mental mechanisms that deliver causal judgement. Hume says that the two definitions 'are only different, by their presenting a different view of the same object, and making us consider it either as a philosophical or a natural relation; either as a comparison of two ideas, or as an association betwixt them' ( $\mathrm{T}$ 1.3.14.31/170). If we take this claim at face value, the suggestion seems to be that (1), rather than characterising how the world has to be in order for a causal claim to be true, or to generate a causal judgement, in fact characterises a mental phenomenon: that of comparing the ideas of two events and thereby coming to judge that one caused the other (this being causation 'considered as a philosophical relation'). Note here that (1) refers to objects that are 'plac' $d$ in like 
relations of precedency and contiguity' (my italics); and 'placing' is something we do. By contrast, (2) characterises a distinct mechanism that delivers causal judgement the habit of inference generated by experienced constant conjunction. This is causation 'considered as a natural relation'.

A third position - that of Strawson - is that 'the two definitions of cause give an account of the content of the idea's impression-sources. They give information about what we positively-contentfully mean, and indeed about all we can really (positively-contentfully) mean, according to the theory of ideas, when we talk about causes. Strawson's interpretation is closer than the previous two to the thought that the two definitions specify the meaning of 'cause'; but Strawson distinguishes between what we can 'positively-contentfully' mean and what the idea of causation refers to. So, in Strawson's view, Hume's suggestion that the definitions may be thought to be defective because 'drawn from objects foreign to the cause' is a recognition of the fact that no specification of causation's true nature - something one might want a definition of causation to do - is beyond our cognitive powers.

What all of these three interpretative positions share is the implication that the two definitions, just by themselves, are in fact neutral between the various interpretative options surveyed above concerning Hume's considered view on the nature of causation. Taking the Craig/Garrett line first, the circumstances under which we (or an idealised observer) come to make causal judgement may or may not reflect causation's true nature. The idealised observer is only human, and therefore is only idealised in the sense of never observing misleading regularities; they do not possess the superhuman power of ascertaining whether or not there are any secret (to us humans) causal powers. Similarly, my own interpretative take specifies only the mental processes whereby we do (or should) come to make causal judgements; the true nature of causation may or may not be reflected in those processes. (Whether or not there are secret powers, and whether or not Hume takes these to be essential features of causation, makes no difference to how it is that we, who are insensitive to such things, come to make causal judgements.) Finally, Strawson's interpretation of the two definitions themselves (as opposed to Hume's remarks about their being 'esteem'd defective'), while part of an argument intended to cast doubt on a meaningempiricist interpretation of Hume, is fully consistent with that interpretation; the meaning-empiricist line simply makes the further claim that the nature of causation is 
fully captured by our 'positively-contentful' idea of it (so that the definitions may be esteemed defective, but in fact are not).

The two definitions just by themselves, then - at least according to several recent interpretations thereof - settle nothing when it comes to the controversy surrounding the nature of causation and the meaning of 'cause'.

\section{Concluding remarks}

What explains the fact that Hume's own words lend themselves to such radically different interpretations? Doubtless the philosophical preferences of his interpreters play a role - generally speaking, interpreters seem to avoid attributing a view to Hume that is obviously false by their own lights, and this is unlikely to be a coincidence. Differences between the Treatise and the Enquiry play a role too; Strawson, for example, argues that Hume's considered views are those expressed in the Enquiry, where he sounds (to my ears, and to Strawson's too) rather more sceptical-realist than he does in the Treatise (see Strawson 2000, §2 and Beebee 2006, $\S 7.8$ ). On the other hand, Peter Millican takes Hume's discussion of free will in $\S 8$ of the Enquiry to deliver 'a torpedo into the core of the New Humeans' position' (Millican 2007, 193; see also Millican 2010); and Peter Kail takes Hume's discussion of the self in the Appendix to the Treatise to 'tip the balance firmly in favour of realism' $(2007,124)$.

Another possible explanation of the apparently intractable interpretative dispute might simply be that Hume is not especially interested in many of the issues that divide the interpretative positions. It can be agreed on all sides that his major epistemological interest when it comes to causation is to show that there are no causal principles knowable a priori, and that it is only by experience that we can come to discover the causal structure of the world. The success of his arguments against rival philosophical positions - occasionalism in $\S 7$ of the Enquiry and libertarianism in $\S 8$ - and various theological positions (arguments for the existence of God in the Dialogues concerning Natural Religion and the existence of miracles in $\S 10$ of the Enquiry) arguably depend on elements of his position that the various different interpretations agree on - that we cannot draw a distinction between causes and occasions, for example, or that human actions are subject to the same species of necessity as are the movements of billiard balls (though Strawson disputes the point 
about occasionalism (see Strawson 1989, Ch. 20, and Beebee 2006, §7.3) and Millican disputes the point about libertarianism; see above).

Scepticism of a kind is also present in all of the interpretative positions. Some sceptical realist commentators have complained that the traditional, regularity-theory interpretation of Hume fails to attribute to him a suitably sceptical position, since on that view there is nothing ungraspable or unknowable about the nature of causation (see e.g. Craig 1987, 129-30; Strawson 1989, 10-14). But we can resist this claim. Interpretations that hold Hume to a meaning-empiricist line can perfectly well construe Hume as holding that our cognitive powers are so limited that we cannot so much as formulate a coherent question about causation's underlying nature ('[w]e have no idea of this connexion, nor even any distinct notion what it is we desire to know, when we endeavour at a conception of it' (EU 7.29/77)), and hence as holding that our actual causal talk and thought cannot latch onto any such thing. Pace Strawson, such intepretations are not committed to construing Hume as holding that there definitely is not, or could not be, some further relation between causes and effects that beings with superior cognitive powers might be able to grasp. Even qua non-sceptical-realist, then, Hume's position enshrines a kind of cognitive modesty that deserves, I think, to be called 'sceptical'. ii

If all this is right, then perhaps it is not so surprising that Hume fails to state the precise semantic content of the idea of causation, and hence fails to say anything that can be decisively interpreted as favouring one semantic position rather than another.

\section{Bibliography}

Anscombe, G. E. M. (1971). Causality and Determination: An Inaugural Lecture. Cambridge: Cambridge University Press. Reprinted in E. Sosa and M. Tooley (eds), Causation, Oxford: Oxford University Press, 1993.

Beauchamp, T. L., \& A. Rosenberg (1981). Hume and the Problem of Causation. New York: Oxford University Press.

Beebee, H. (2006). Hume on Causation. Abingdon: Routledge.

-- (2011). 'Hume's Two Definitions: The Procedural Interpretation'. Hume Studies, 37: $243-74$.

Berkeley, G. (1710). A Treatise Concerning the Principles of Human Knowledge, ed. J. Dancy. Oxford: Oxford University Press, 1998. 
Buckle, S. (2001). Hume's Enlightenment Tract. Oxford: Oxford University Press. Coventry, A. (2006). Hume's Theory of Causation. New York: Continuum Press. Craig, E. (1987). The Mind of God and the Works of Man. Oxford: Clarendon Press. -- (2000). 'Hume on Causality: Projectivist and Realist?', in Read and Richman (2000), 113-21

Descartes, R. (1641). Meditations on First Philosophy, trans and ed. J. Cottingham. Cambridge: Cambridge University Press (1996).

Flage, D. (2000). 'Relative Ideas Re-viewed', in Read and Richman (2000) 138-55. Garrett, D. (1997). Cognition and Commitment in Hume's Philosophy. Oxford:

Oxford University Press.

-- (2009). 'Hume', in H. Beebee, C. Hitchcock \& P. Menzies (eds), The Oxford Handbook of Causation. Oxford: Oxford University Press.

Jacobson, A. J. (2000). 'From Cognitive Science to Post-Cartesian Text: What Did Hume Really Say?', in Read and Richman (2000), 156-66.

Joyce, R. (2009). 'Moral Anti-Realism', in E. N. Zalta (ed.), The Stanford Encyclopedia of Philosophy (Summer 2009 Edition). URL = $<$ http://plato.stanford.edu/archives/sum2009/entries/moral-anti-realism/>. Kail, P. (2007). Projection and Realism in Hume's Philosophy. Oxford: Oxford University Press.

-- (2008). 'Review of H. Beebee, Hume on Causation', Mind, 117: 451-6.

Kemp Smith, N. (1941). The Philosophy of David Hume. London: Macmillan.

Mackie, J. L. (1974). The Cement of the Universe. London: Oxford University Press. Millican, P. (2007). 'Humes Old and New: Four Fashionable Falsehoods, and One Unfashionable Truth'. Proceedings of the Aristotelian Society, Supp. Vol. 81: 163-99.

-- (2010). 'Hume, Causal Realism, and Free Will', in K. Allen \& T. Stoneham (eds), Causation and Modern Philosophy. New York: Routledge.

Mumford, S. \& R. Lil Anjum. (2011). Getting Causes from Powers. Oxford: Oxford University Press.

Price, H. (1998). 'Two paths to pragmatism II', in R. Casati and C. Tappolet (eds), European Review of Philosophy, 3: 109-47.

Psillos, S. (2009). 'Regularity Theories', in H. Beebee, C. Hitchcock \& P. Menzies (eds), The Oxford Handbook of Causation. Oxford: Oxford University Press. Read, R. and K. Richman (eds) (2000). The New Hume Debate. London: Routledge. 
Russell, B. (1912-13). 'On the Notion of Cause', Proceedings of the Aristotelian Society, 13: 1-26.

Strawson, G. (1989). The Secret Connexion. Oxford: Oxford University Press.

-- (2000) 'David Hume: Objects and Power', in Read and Richman (2000), 31-51.

Stroud, B. (1977). Hume. London: Routledge.

Wilson, F. (1986). 'Hume's Defence of Science', Dialogue, XXV: 611-28.

Winkler, K. (2000). 'The New Hume', in Read and Richman (2000), 52-87.

-- (2010). 'P. J. E. Kail's Projection and Realism in Hume's Philosophy',

Philosophical Books, 51: 144-59.

Wright, J. P. (1983). The Sceptical Realism of David Hume. Manchester: Manchester University Press.

-- (2000). 'Hume’s Causal Realism', in Read and Richman (2000), 88-99.

\section{Endnotes}

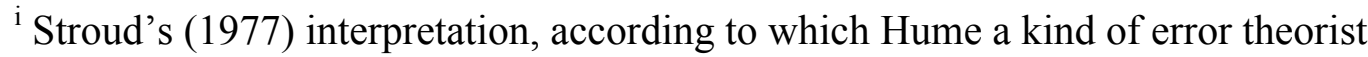
about causation, sits somewhere between the traditional and projectivist interpretations. On Stroud's view, the idea of necessary connection is defective, but we cannot help but deploy it. So Stroud agrees with the projectivist interpretation that the idea of necessary connection plays a semantic role in our causal talk, but agrees with the traditional interpretation that that idea is irredeemably defective.

${ }^{\text {ii }}$ Kail (2008, 455-6) disputes whether a meaning-empiricist line really allows Hume the semantic scope to formulate a genuinely sceptical thought here; see also Kail 2007, §4.3. 